\title{
LITTLE BLUE HERON IN SASKATCHEWAN
}

WAYNE C. HARRIS and SHEILA M. LAMONT, Box 994, Prince Albert, Saskatchewan S6V 5 S5

On June 19, 1976, an adult Little Blue Heron was sighted by the authors at the north end of Last Mountain Lake. The bird was approximately 100 yards away, standing at the edge of a shallow pool just behind a dam at the mouth of Lanigan Creek. The dam was open and no water was being held within the reservoir, resulting in large mudflats with scattered pools of water.

The bird was first spotted at about 1830 and watched for about 10 minutes in full sunlight at a distance of 100 yards with a $45 X$ spotting scope and $8 \times 35$ and $7 \times 35$ binoculars. The following description was recorded: "A small heron. Color of body, wings and tail, was slaty blue, with the neck and head showing a maroon tinge. The bill was blue and legs were slaty blue. The eye was dark. Body size similar to that of a nearby mallard." The bird's activities were minimal resting, with a brief period of preening.

Several color slides were taken from 100 yards with a $210 \mathrm{~mm}$ telephoto lens, and then while attempting to stalk the bird it flu before any more photos could be tained. It flew directly over Harr close as 10 yards and was last seen day as it flew south along the shore of Last Mountain Lake.

The bird was on the same mu behind the dam the next day at It was again studied carefully w $45 X$ spotting scope from as close yards. Several more color slides obtained. The bird was again flu and flew southwest across the Visits were made later in the $m$ but the bird was not seen.

Previous observations Saskatchewan are as follows: The was four seen by Joyce Gunn at $C$ Spirit Lake on May 24, 1956. A s bird, seen by many observers, present sporadically from Septei 9 to September 21, 1956, at Cre Lake, 16 miles south of Yor There is also a 1956 report of birds, thought to be breeding, a cola. ${ }^{1}$

'HOUSTON, STUART. 1957. The Littl Heron in Saskatchewan. Blue Jay

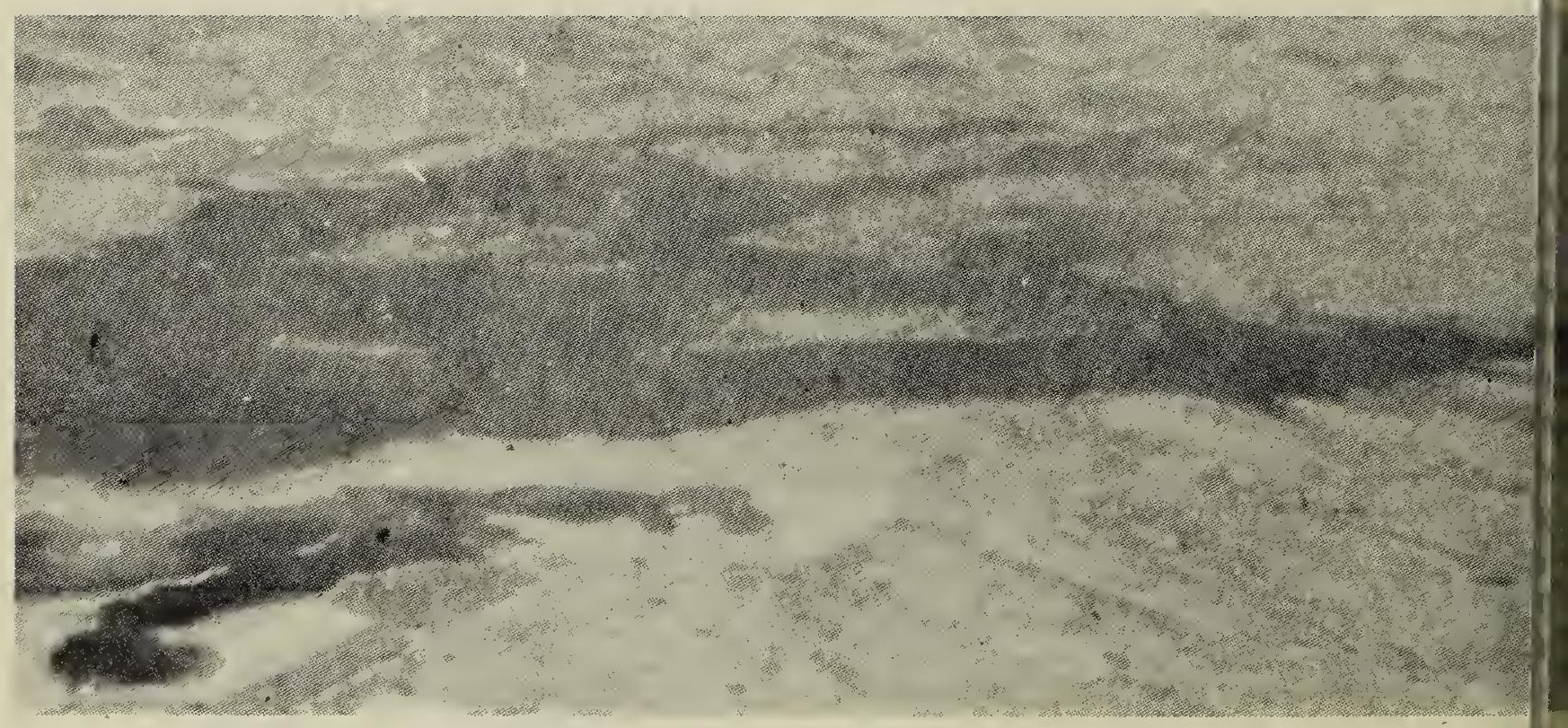

North end, Last Mountain Lake

J. B. III 